\title{
Modelling Biogrout: A New Ground Improvement Method Based on Microbial-Induced Carbonate Precipitation
}

\author{
W. K. van Wijngaarden - F. J. Vermolen • \\ G. A. M. van Meurs • C. Vuik
}

Received: 29 July 2009 / Accepted: 25 November 2010 / Published online: 17 December 2010

(C) The Author(s) 2010. This article is published with open access at Springerlink.com

\begin{abstract}
Biogrout is a new soil reinforcement method based on microbial-induced carbonate precipitation. Bacteria are placed and reactants are flushed through the soil, resulting in calcium carbonate precipitation, causing an increase in strength and stiffness of the soil. Due to this precipitation, the porosity of the soil decreases. The decreasing porosity influences the permeability and therefore the flow. To analyse the Biogrout process, a model was created that describes the process. The model contains the concentrations of the dissolved species that are present in the biochemical reaction. These concentrations can be solved from a advection-dispersion-reaction equation with a variable porosity. Other model equations involve the bacteria, the solid calcium carbonate concentration, the (decreasing) porosity, the flow and the density of the fluid. The density of the fluid changes due to the biochemical reactions, which results in density driven flow. The partial differential equations are solved by the Standard Galerkin finite-element method. Simulations are done for some 1D and 2D configurations. A $1 \mathrm{D}$ configuration can be used to model a column experiment and a $2 \mathrm{D}$ configuration may correspond to a sheet or a cross section of a 3D configuration.
\end{abstract}

Keywords Biogrout - Microbial-induced carbonate precipitation - Density flow · Finite-element method · Decreasing porosity

\section{List of Symbols}

$C^{\text {urea }} \quad$ Concentration of dissolved urea molecules $\left(\mathrm{kmol} / \mathrm{m}^{3}\right)$

$C^{\mathrm{Ca}^{2+}} \quad$ Concentration of dissolved calcium ions $\left(\mathrm{kmol} / \mathrm{m}^{3}\right)$

$\mathrm{C}^{\mathrm{NH}_{4}^{+}} \quad$ Concentration of dissolved ammonium ions $\left(\mathrm{kmol} / \mathrm{m}^{3}\right)$

$C^{\mathrm{CaCO}_{3}}$ Concentration of calcium carbonate molecules $\left(\mathrm{kg} / \mathrm{m}^{3}\right)$

W. K. van Wijngaarden · F. J. Vermolen · C. Vuik

Delft Institute of Applied Mathematics, Delft University of Technology,

Mekelweg 4, 2628 CD Delft, The Netherlands

W. K. van Wijngaarden $(\varangle) \cdot$ G. A. M. van Meurs

Deltares, Unit Geo Engineering, Stieltjesweg 2, 2628 CK Delft, The Netherlands

e-mail: Miranda.vanWijngaarden@Deltares.nl 


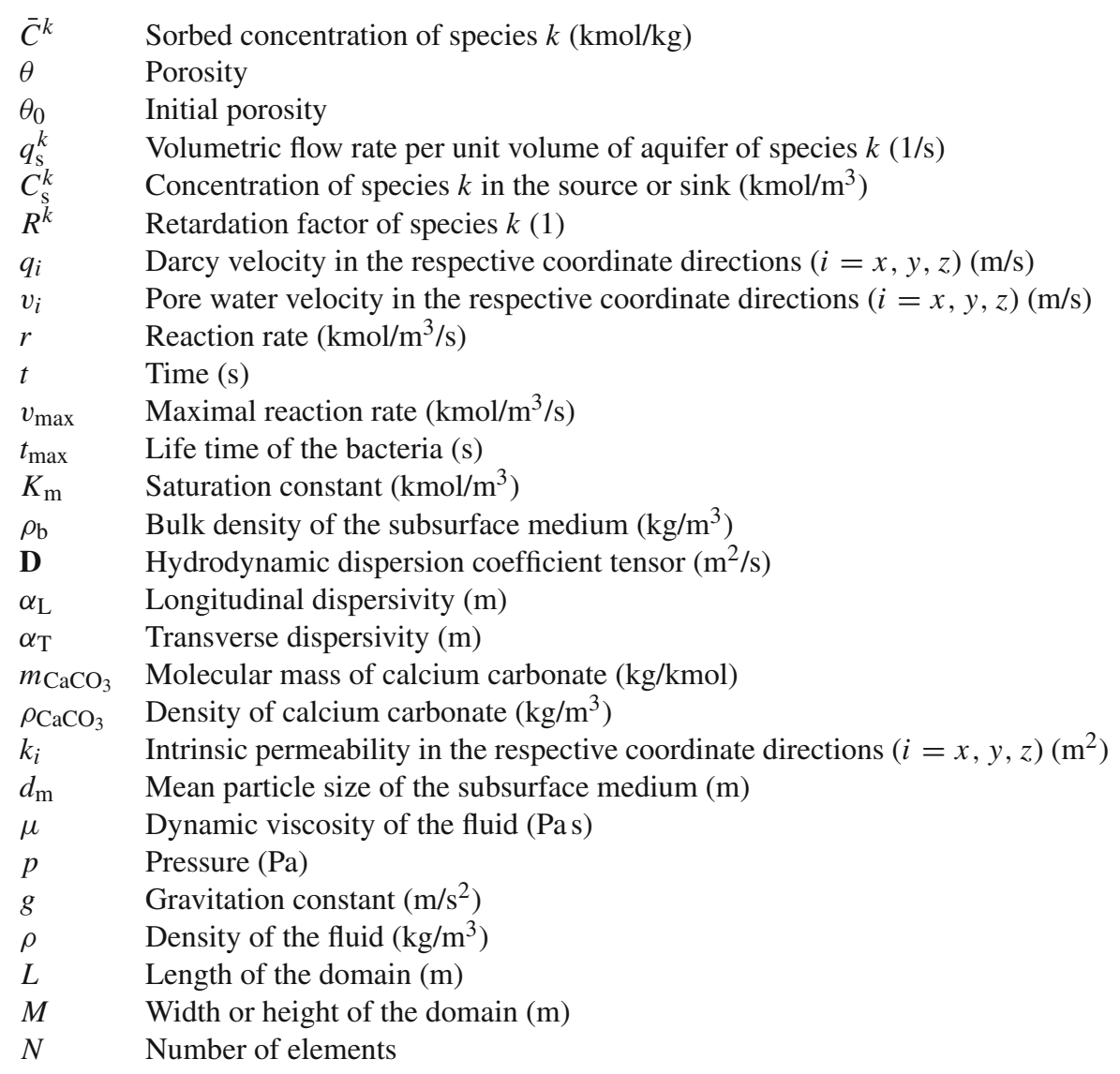

\section{Introduction}

Biogrout is a new soil reinforcement method based on microbial-induced carbonate precipitation (MICP), see, among others, Whiffin et al. (2007) and Van Paassen (2009).

Precipitation of calcium carbonate $\left(\mathrm{CaCO}_{3}\right)$ occurs when a solution is oversaturated, i.e. the amount of calcium $\left(\mathrm{Ca}^{2+}\right)$ and carbonate ions $\left(\mathrm{CO}_{3}{ }^{2-}\right)$ in solution exceeds the solubility product. According to Van Paassen (2009), the role of micro-organisms in calcium carbonate precipitation is attributed to producing carbonate (e.g. by hydrolysis, respiration, etc.) and acting as nucleation sites for the formation of crystals in an already oversaturated solution.

Several researchers have shown that MICP can be used to improve the mechanical properties of porous materials (Nemati and Voordouw 2003; DeJong et al. 2006; Whiffin et al. 2007; Van Paassen 2009). Most studies on MICP for soil stabilization, use micro-organisms containing the enzyme urease and in particular the bacteria Sporosarcina pasteurii. First, these micro-organisms are cultivated. Subsequently, they are injected and transported by water flow to the location where strengthening is required. In order to prevent crystal accumulation around the injection point and to get a more homogeneous distribution of calcium carbonate over a large distance, only after bacterial placement the urea $\left(\mathrm{CO}\left(\mathrm{NH}_{2}\right)_{2}\right)$ and calcium chloride $\left(\mathrm{CaCl}_{2}\right)$ solution is supplied (Whiffin et al. 2007). Urease catalyses the hydrolysis of urea into ammonium $\left(\mathrm{NH}_{4}{ }^{+}\right)$and carbonate. The produced carbonate ions precipitate in 
the presence of calcium ions as calcium carbonate and form crystals. These crystals form bridges between the sand grains, by which the soil is strengthened. The remaining ammonium chloride $\left(\mathrm{NH}_{4} \mathrm{Cl}\right)$ has to be removed.

In Whiffin et al. (2007), the reaction equation for the hydrolysis of urea is given by

$$
\mathrm{CO}\left(\mathrm{NH}_{2}\right)_{2}(\mathrm{aq})+2 \mathrm{H}_{2} \mathrm{O}(\mathrm{l}) \stackrel{\text { bacteria }}{\longrightarrow} 2 \mathrm{NH}_{4}{ }^{+}(\mathrm{aq})+\mathrm{CO}_{3}{ }^{2-}(\mathrm{aq}) \text {. }
$$

The precipitation of calcium carbonate happens in several steps, depending on the $\mathrm{pH}$. The overall reaction equation is given by:

$$
\mathrm{Ca}^{2+}(\mathrm{aq})+\mathrm{CO}_{3}{ }^{2-}(\mathrm{aq}) \rightarrow \mathrm{CaCO}_{3}(\mathrm{~s}) .
$$

Combining the reaction equation for the production of carbonate, (1), and the reaction equation for the precipitation of calcium carbonate, (2), gives the overall Biogrout reaction equation:

$$
\mathrm{CO}\left(\mathrm{NH}_{2}\right)_{2}(\mathrm{aq})+\mathrm{Ca}^{2+}(\mathrm{aq})+2 \mathrm{H}_{2} \mathrm{O}(\mathrm{l}) \rightarrow 2 \mathrm{NH}_{4}{ }^{+}(\mathrm{aq})+\mathrm{CaCO}_{3}(\mathrm{~s}) .
$$

Biogrout can be applied to a wide variety of situations, in which it is desirable to change the properties of the subsoil, see DeJong et al. (2009). A large advantage of Biogrout is that the method can be applied without excavation or replacement of the subsoil. Furthermore, the subsoil does not become impermeable.

Since reinforcement is an important issue, the Biogrout process parameters should be chosen carefully. Therefore, a thorough understanding of the process is crucially important. The following parameters play a major role in the Biogrout process:

- the concentrations of urea, calcium chloride, ammonium chloride and calcium carbonate, which change due to dispersion, advection and reaction;

- the density of the solution, which changes due to its altering composition;

- porosity and permeability, which decrease as a result of the precipitation of the solid calcium carbonate;

- flow through the porous medium, which is influenced by injection, extraction and changing density, porosity and permeability, in which the changes of the porosity and permeability are caused by the precipitation of calcium carbonate.

All these parameters have been combined in the current model. This model can be used to predict the location and level of precipitated calcium carbonate as a function of the process parameters. In order to accomplish a high level of insight into all these parameters, a combination of modelling and well-conducted experiments is indispensable.

The current model is inspired by the study of Zheng and Bennett (1995). In Chapter 2 and 3 of aforementioned book, the advection-diffusion-reaction differential equation in saturated porous media has been derived for a time-independent porosity. In the Biogrout case, the porosity is time dependent. Hence, to get the right differential equation for the concentration of urea, ammonium and calcium, this derivation should be repeated for a timedependent porosity. Also, the differential equation for the (non-aqueous) calcium carbonate concentration should be derived. Of course, the flow should also be known. The flow can be calculated from a differential equation for it. Another possibility is to calculate the flow from a differential equation for the pressure, since the pressure is related to the flow by Darcy's Law, derived in Chapter 1 of Zheng and Bennett (1995). Since the boundary conditions are often given in terms of pressure and the density of the fluid is not constant, it is 
better to calculate the flow from a differential equation for the pressure. Hence, a differential equation for the pressure should be derived. Because of the decreasing porosity, this is not really trivial. To use Darcy's Law, the intrinsic permeability should be known. For a relation between the intrinsic permeability and the porosity, Bear (1972) has been used. Further, for a relation between the density and the various concentrations, Weast (1980) has been used.

In Zienkiewicz et al. (2005) is explained how differential equations can be solved with the finite-element method. The partial differential equations that are derived are (nonlinear) hyperbolic differential equations. Lohner et al. (1984) provide a method to solve this kind of differential equations with finite elements. If the transport equations are advection dominated, instead of the Standard Galerkin (SG) method a Streamline Upwind Petrov Galerkin (SUPG) method can be used to get a stable solution, see for instance, Le Beau et al. (1991), Heinrich et al. (1977) and Ewing and Wang (2001). Also the Discontinuous Galerkin (DG) method can be applied, see Atkins and Shu (1998) and Cockburn (1998), preferably with slope limiters, see for instance, Cockburn and Shu (1998) and Krivodonova (2007). In Lichtner et al. (1996) and Celia et al. (1989), several numerical methods are applied to model reactive transport in porous media.

This article contains the following. Section 2 describes the model for the Biogrout process and gives an exact solution for a special case. The model is based on the overall Biogrout reaction Eq. 3. Furthermore, in Sect. 2 partial differential equations are derived to describe the concentration of all the species in this reaction equation. Due to the precipitation of calcium carbonate, the porosity decreases. A relation between the calcium carbonate concentration and the porosity is also given in Sect. 2, just like the derivation of the flow equations. Under particular conditions, an exact solution can be found. The derivation of this solution can be found in Subsect. 2.2. Section 3 is devoted to the numerical methods that are used. Section 4 contains some computer simulations and in Sect. 5 some conclusions and discussion can be found. All the symbols used in this article have been listed under List of Symbols.

\section{The Mathematical Model}

In Subsect. 2.1, the differential equations that are needed to describe the Biogrout process are derived. In Subsect. 2.2, an exact solution for the porosity and the calcium carbonate concentration is derived for a special case.

\subsection{Derivation of the Differential Equations}

In this section, a model is developed for the Biogrout process. The differential equations are derived for the concentrations of the various species, for the porosity and for the flow. These differential equations are derived under the assumptions that:

1. Only dissolved species react;

2. The reaction consists of sorption, an hydrolysis reaction and a precipitation reaction;

3. The equilibrium between the sorbed and the dissolved phase is reached instantaneously;

4. The biochemical reaction of the Biogrout process is governed by reaction (3) and is also assumed to take place instantaneously;

5. Calcium carbonate is not transported but it precipitates on the matrix of the porous medium; 
6. The fluid is incompressible;

7. The hydrolysis of urea and the precipitation of calcium carbonate have no influence on the total volume of the fluid over the entire domain of computation;

8. The viscosity is constant.

\subsubsection{The Differential Equations for the Aqueous Species: Urea, Calcium Chloride and Ammonium Chloride}

First, the differential equations for the aqueous species are derived. In Zheng and Bennett (1995), the advection-dispersion-reaction equation for the transport of a solute species in porous media has been derived for a time-independent porosity. Following this derivation, but now for a time-dependent porosity and under assumption 2, the following differential equation is derived:

$$
R \theta \frac{\partial C}{\partial t}=\nabla \cdot(\theta \mathbf{D} \cdot \nabla C)-\mathbf{q} \cdot \nabla C+q_{\mathrm{s}} C_{\mathrm{s}}-\left(\frac{\partial \theta}{\partial t}+\nabla \cdot \mathbf{q}\right) C+\theta m r,
$$

where the retardation factor is given by

$$
R=1+\frac{\rho_{\mathrm{b}}}{\theta} \frac{\partial \bar{C}}{\partial C}
$$

In these equations, $C$ is the dissolved concentration of the species (per pore volume), $\bar{C}$ is the sorbed concentration, $\theta$ is the porosity, $\mathbf{D}$ is the dispersion tensor, $\mathbf{q}$ is the Darcy velocity, $q_{\mathrm{s}}$ is the volumetric flow rate, representing fluid sources (positive) and sinks (negative), $C_{\mathrm{s}}$ is the concentration of the source or sink, $r$ is the reaction rate of Eq. 3, $m$ is some constant and $\rho_{\mathrm{b}}$ is the bulk dry density.

The term at the left-hand side of Eq. 4 represents the accumulation and contains the retardation factor $R$, which is a measure for the retarding effect of sorption. The first term at the right-hand side represents the effect of dispersion and diffusion, the second-term models advection and the third term represents a source or a sink. The fourth term is a result of the chain rule, applied on the accumulation term and the advection term. The last term represents the rate of change in solute mass (or moles) of a particular species due to the reaction as given in Eq. 3.

In one dimension, the dispersion tensor is given by $\mathbf{D}=\alpha_{\mathrm{L}}|\mathbf{v}|$. In more dimensions, the coefficients of the dispersion tensor $\mathbf{D}$ are represented by $D_{i j}=\left(\alpha_{\mathrm{L}}-\alpha_{\mathrm{T}}\right) \frac{v_{i} v_{j}}{|\mathbf{v}|}+\delta_{i j} \alpha_{\mathrm{T}} \sum_{i} \frac{v_{i}^{2}}{|\mathbf{v}|}$, see Zheng and Bennett (1995). The quantity $\alpha_{\mathrm{L}}$ is the longitudinal dispersivity and $\alpha_{\mathrm{T}}$ is the transverse dispersivity. The quantity $\delta_{i j}$ is the Kronecker delta that equals 1 if $i=j$ and 0 otherwise. The factor $\mathbf{v}$ is the pore water velocity and the relation with the Darcy velocity, $\mathbf{q}$, is given by: $\mathbf{v}=\frac{\mathbf{q}}{\theta}$. The quantity $r=r\left(C^{\mathrm{urea}}, C^{\mathrm{NH}_{4}^{+}}, C^{\mathrm{Ca}^{2+}}, C^{\mathrm{CaCO}_{3}}, \theta, t\right)$ is the reaction rate of the reaction given in Eq. 3 (in mole per pore volume per unit of time) and is possibly a nonlinear function of the concentrations, the porosity and time. The value of the constant $m$ differs from species to species and follows from the relation between the reactants and products in reaction Eq. 3. The value of $m$ for calcium carbonate is given by $m=1$, since calcium carbonate is formed at a rate $r$. If one mole of calcium carbonate is formed, two moles of ammonium are formed and one mole of calcium and one mole of urea are consumed. Hence, in the differential equation for ammonium, the value $m=2$ is used and in the differential equation for calcium and urea, the value $m=-1$ is used. This gives the following differential equations for urea, calcium chloride and ammonium chloride: 


$$
\begin{aligned}
& R^{\text {urea }} \theta \frac{\partial C^{\text {urea }}}{\partial t}=\nabla \cdot\left[\theta \mathbf{D} \cdot \nabla C^{\text {urea }}\right]-\mathbf{q} \cdot \nabla C^{\text {urea }}+q_{\mathrm{s}}^{\text {urea }} C_{\mathrm{s}}^{\text {urea }} \\
& -\left(\frac{\partial \theta}{\partial t}+\nabla \cdot \mathbf{q}\right) C^{\text {urea }}-\theta r \\
& \text { in which } R^{\text {urea }}=1+\frac{\rho_{\mathrm{b}}}{\theta} \frac{\partial \bar{C}^{\text {urea }}}{\partial C^{\text {urea }}} \text {, } \\
& R^{\mathrm{Ca}^{2+}} \theta \frac{\partial C^{\mathrm{Ca}^{2+}}}{\partial t}=\nabla \cdot\left[\theta \mathbf{D} \cdot \nabla C^{\mathrm{Ca}^{2+}}\right]-\mathbf{q} \cdot \nabla C^{\mathrm{Ca}^{2+}}+q_{\mathrm{s}}^{\mathrm{Ca}^{2+}} C_{\mathrm{s}}^{\mathrm{Ca}^{2+}} \\
& -\left(\frac{\partial \theta}{\partial t}+\nabla \cdot \mathbf{q}\right) C^{\mathrm{Ca}^{2+}}-\theta r \\
& \text { in which } R^{\mathrm{Ca}^{2+}}=1+\frac{\rho_{\mathrm{b}}}{\theta} \frac{\partial \bar{C}^{\mathrm{Ca}^{2+}}}{\partial C^{\mathrm{Ca}^{2+}}} \text { and } \\
& R^{\mathrm{NH}_{4}{ }^{+}} \theta \frac{\partial C^{\mathrm{NH}_{4}+}}{\partial t}=\nabla \cdot\left[\theta \mathbf{D} \cdot \nabla C^{\mathrm{NH}_{4}{ }^{+}}\right]-\mathbf{q} \cdot \nabla C^{\mathrm{NH}_{4}{ }^{+}}+q_{\mathrm{s}}^{\mathrm{NH}_{4}^{+}} C_{\mathrm{s}}^{\mathrm{NH}_{4}+} \\
& -\left(\frac{\partial \theta}{\partial t}+\nabla \cdot \mathbf{q}\right) C^{\mathrm{NH}_{4}^{+}}+2 \theta r \\
& \text { in which } R^{\mathrm{NH}_{4}^{+}}=1+\frac{\rho_{\mathrm{b}}}{\theta} \frac{\partial \bar{C}^{\mathrm{NH}_{4}^{+}}}{\partial C^{\mathrm{NH}_{4}{ }^{+}}} \text {. }
\end{aligned}
$$

\subsubsection{The Differential Equation for the Non Aqueous Species: Calcium Carbonate}

Next, a differential equation is derived for the concentration of the non-aqueous calcium carbonate. Once calcium carbonate is generated, it immediately precipitates and attaches onto the matrix of the porous medium. Therefore, its concentration is defined in terms of weight per unit volume (and not per unit pore volume). Since it has been assumed that the calcium carbonate will not be transported, the concentration of calcium carbonate will only be changed by the biochemical reaction. Consider a small box. The number of calcium carbonate ions per pore volume that will be formed in this small box in time $\Delta t$ is given by $r \Delta t$. The number of kilograms of calcium carbonate ions per total volume within time period $\Delta t$ is given by $\Delta C^{\mathrm{CaCO}_{3}}=m_{\mathrm{CaCO}_{3}} \theta r \Delta t$, where $m_{\mathrm{CaCO}_{3}}$ is the molar mass of calcium carbonate. Dividing by $\Delta t$ and taking the limit of $\Delta t \rightarrow 0$ gives the following differential equation for the concentration of calcium carbonate:

$$
\frac{\partial C^{\mathrm{CaCO}_{3}}}{\partial t}=m_{\mathrm{CaCO}_{3}} \theta r .
$$

\subsubsection{The Differential Equation for the Porosity}

Since the pore volume is being filled with calcium carbonate, the porosity [which is, by definition, the pore volume per total volume $\left.\left(V_{\text {pore }} / V_{\text {total }}\right)\right]$ decreases. The change in porosity, $\Delta \theta=-\frac{\Delta V_{\text {pore }}}{V_{\text {total }}}=-\frac{\Delta C C_{\mathrm{CaCO}_{3}}}{\rho_{\mathrm{CaCO}_{3}}}$, in which $\rho_{\mathrm{CaCO}_{3}}$ is the density of calcium carbonate. If this change is considered per time $\Delta t$, subsequently taking the limit of $\Delta t \rightarrow 0$, the following differential equation is obtained for the porosity:

$$
\frac{\partial \theta}{\partial t}=-\frac{1}{\rho_{\mathrm{CaCO}_{3}}} \frac{\partial C^{\mathrm{CaCO}_{3}}}{\partial t} .
$$


Solving this differential equation gives:

$$
\theta(t)=\theta(0)-\frac{C^{\mathrm{CaCO}_{3}}(t)-C^{\mathrm{CaCO}_{3}}(0)}{\rho_{\mathrm{CaCO}_{3}}} .
$$

Hence, if the concentration of calcium carbonate is known, subsequently the porosity can be calculated.

\subsubsection{The Differential Equations for the Flow}

It has been assumed that the fluid is incompressible and that the hydrolysis of urea and the precipitation of calcium carbonate have no influence on the total volume of the fluid over the entire domain of computation (assumption 6 and 7). These two assumptions imply that there is conservation of fluid volume.

Due to the precipitation of calcium carbonate, the pore space decreases. Hence, the nett fluid flow through $\Gamma_{\epsilon}$, the boundary of any control volume $\Omega_{\epsilon}$ in the computational domain $\Omega$, must equal the decrease in pore volume in $\Omega_{\epsilon}$ per unit of time. Hence:

$$
\int_{\Gamma_{\epsilon}} \mathbf{q} \cdot \mathbf{n} \mathrm{d} \Gamma=-\int_{\Omega_{\epsilon}} \frac{\partial \theta}{\partial t} \mathrm{~d} \Omega .
$$

Applying the divergence theorem of Gauss to the left-hand side of (12) gives

$$
\int_{\Omega_{\epsilon}} \nabla \cdot \mathbf{q} \mathrm{d} \Omega=-\int_{\Omega_{\epsilon}} \frac{\partial \theta}{\partial t} \mathrm{~d} \Omega .
$$

Equation 13 holds for any $\Omega_{\epsilon} \subseteq \Omega$ and hence

$$
\nabla \cdot \mathbf{q}=-\frac{\partial \theta}{\partial t} .
$$

Substituting (9) into (10) and substituting the result into (14), gives the following differential equation for the flow:

$$
\nabla \cdot \mathbf{q}=\frac{m_{\mathrm{CaCO}_{3}}}{\rho_{\mathrm{CaCO}_{3}}} \theta r .
$$

In Zheng and Bennett (1995), Darcy's Law is given by:

$$
\begin{aligned}
q_{x} & =-\frac{k_{x}}{\mu} \frac{\partial p}{\partial x}, \\
q_{y} & =-\frac{k_{y}}{\mu} \frac{\partial p}{\partial y}, \\
q_{z} & =-\frac{k_{z}}{\mu}\left(\frac{\partial p}{\partial z}+\rho g\right) .
\end{aligned}
$$

In Darcy's Law, $p$ is the pressure, $k$ is the intrinsic permeability in the various coordinate directions, $\mu$ is the viscosity that is assumed to be constant in the Biogrout case and $\rho$ is the density of the solution.

Substituting (16) into (15), using (18), gives the following differential equation for the pressure:

$$
-\nabla \cdot\left(\frac{k}{\mu}\left(\nabla p+\rho g \mathbf{e}_{\mathbf{z}}\right)\right)=\frac{m_{\mathrm{CaCO}_{3}}}{\rho_{\mathrm{CaCO}_{3}}} \theta r .
$$

The resulting pressure is used to calculate the flow, using Darcy's Law (16). 


\subsubsection{The Intrinsic Permeability and the Density}

To calculated the pressure and the flow, the intrinsic permeability and the density of the solution should be known.

The intrinsic permeability is determined, using the Kozeny-Carman relation: an empiric relation between the intrinsic permeability and the porosity that is commonly used in ground water flow modelling (see Bear 1972):

$$
k=k_{x}=k_{y}=k_{z}=\frac{\left(d_{\mathrm{m}}\right)^{2}}{180} \frac{\theta^{3}}{(1-\theta)^{2}} .
$$

In this relation, $d_{\mathrm{m}}$ is the mean particle size of the subsurface medium. If the porosity is very low, it might be that the pores are not connected. Hence, the intrinsic permeability is zero. This phenomenon is not directly incorporated in the Kozeny-Carman relation (Jan M. Nordbotten, 2009, Personal communication). If the porosity is close to zero, the Kozeny-Carman relation behaves as a third-order polynomial. and the permeability is almost zero, although not equal to zero. Since in the simulations of the Biogrout process the porosity is higher than 0.12 , the use of the Kozeny-Carman relation is maintained.

The density of the solution (at $20^{\circ} \mathrm{C}$ ) will be calculated with the following experimental relation:

$$
\rho=1,000+15.4996 C^{\text {urea }}+86.7338 C^{\mathrm{Ca}^{2+}}+15.8991 C^{\mathrm{NH}_{4}^{+}} .
$$

This relation has been found, using Weast (1980). From the tables of the individual species, a linear relation between the concentration and the density increase has been found. By adding the contributions of the several species, relation (19) was found. Experimental validation showed that this relation is a good description of reality.

\subsubsection{The Reaction Rate}

The reaction rate depends on many factors, like the number of bacteria, growth and storage conditions before use (Whiffin 2004). Conditions in the subsoil can also influence the reaction rate, like the temperature (Bachmeier et al. 2002) and the $\mathrm{pH}$ (Stocks-Fischer et al. 1999; Whiffin 2004). The concentrations of urea, ammonium chloride and calcium chloride might be too high for the bacteria. Encapsulation by calcium carbonate crystals can make a diffusion barrier around the bacteria (Bang et al. 2001). Another point is that aerobic bacteria are injected into an anaerobic subsoil. Due to the lack of oxygen, the bacteria die. All these phenomena make it likely that the reaction rate decreases. This is also shown in experiments (Whiffin et al. 2007).

For the moment a linear decay has been assumed: in $t_{\max }$ seconds the reaction rate decreases from a maximal reaction rate, $v_{\max }$, to zero. The quantity $v_{\max }$ is constant, since the distribution of bacteria is assumed to be homogeneous. Further, the reaction rate equals zero, if there is no urea present and is maximal if an abundant amount of urea is present. The following formula will be used for the reaction rate:

$$
r= \begin{cases}v_{\max } \frac{C^{\text {urea }}}{K_{\mathrm{m}}+C^{\text {urea }}}\left(1-\frac{t}{t_{\max }}\right) & \text { if } 0 \leq t \leq t_{\max } \\ 0 & \text { else }\end{cases}
$$

In this equation, the saturation constant $K_{\mathrm{m}}$ is small. 


\subsubsection{General Perspective and Initial Conditions}

For the aqueous species (urea, calcium and ammonium), differential equations (6), (7) and (8) were derived. For the non-aqueous species (calcium carbonate), differential equation (9) was derived. The porosity can be calculated with formula (11). For the pressure, differential equation (17) was derived. The flow can be calculated with Darcy's law (16). The intrinsic permeability $k$, the density of the solution $\rho$ and the reaction rate $r$ can be calculated with, respectively, formula (18), (19) and (20). The quantities $q_{\mathrm{s}}, C_{\mathrm{s}}, \mathbf{D}, m_{\mathrm{CaCO}_{3}}, \rho_{\mathrm{CaCO}_{3}}, d_{\mathrm{m}}, \mu, g, v_{\max }, t_{\max }, K_{\mathrm{m}}$ and $\frac{\partial \bar{C}}{\partial C}$ are assumed to be known. Initially, the concentration of calcium carbonate, urea, calcium and ammonium are equal to zero. The boundary conditions for the pressure and the concentration of urea, calcium and ammonium are given in Sect. 4, since they differ from case to case. Having these boundary conditions, the equations have a unique solution. How this solution will be approximated, will be explained in Sect. 3. However, first an exact solution will be derived for a special case.

\subsection{Exact Solution for a Special Case}

In this subsection, a formula will be derived to calculate the calcium carbonate concentration as a function of time $\left(0 \leq t \leq t_{\max }\right)$ for a constant urea (and calcium) concentration.

The rate function (20) on this time interval is substituted in the differential equation for the calcium carbonate concentration (9). The result is substituted into the differential equation for the porosity (10):

$$
\frac{\partial \theta}{\partial t}=-\theta r \frac{m_{\mathrm{CaCO}_{3}}}{\rho_{\mathrm{CaCO}_{3}}}=-\theta \frac{m_{\mathrm{CaCO}_{3}}}{\rho_{\mathrm{CaCO}_{3}}} v_{\max } \frac{C^{\text {urea }}}{K_{\mathrm{m}}+C^{\text {urea }}}\left(1-\frac{t}{t_{\max }}\right) .
$$

Solving Eq. 21 by dividing by $\theta$ and integrating from 0 to $t$ gives the following function for the porosity as a function of time:

$$
\theta(t)=\theta_{0} \exp \left\{-\frac{m_{\mathrm{CaCO}_{3}}}{\rho_{\mathrm{CaCO}_{3}}} v_{\max } \frac{C^{\text {urea }}}{K_{\mathrm{m}}+C^{\text {urea }}}\left(t-\frac{t^{2}}{2 t_{\max }}\right)\right\} .
$$

Substituting Eq. 22 and rate function (20) into the differential equation for calcium carbonate, (9), gives

$$
\begin{aligned}
\frac{\partial C^{\mathrm{CaCO}_{3}}}{\partial t}= & m_{\mathrm{CaCO}_{3}} \theta_{0} \exp \left\{-\frac{m_{\mathrm{CaCO}_{3}}}{\rho_{\mathrm{CaCO}_{3}}} v_{\max } \frac{C^{\text {urea }}}{K_{\mathrm{m}}+C^{\text {urea }}}\left(t-\frac{t^{2}}{2 t_{\max }}\right)\right\} \\
& \times\left\{v_{\max } \frac{C^{\text {urea }}}{K_{\mathrm{m}}+C^{\text {urea }}}\left(1-\frac{t}{t_{\max }}\right)\right\} .
\end{aligned}
$$

Solving Eq. 23 by integrating from 0 to $t$, gives the following solution:

$$
\begin{aligned}
C^{\mathrm{CaCO}_{3}}(t)= & C^{\mathrm{CaCO}_{3}(0)} \\
& +\rho_{\mathrm{CaCO}_{3}} \theta_{0}\left\{1-\exp \left\{-\frac{m_{\mathrm{CaCO}_{3}}}{\rho_{\mathrm{CaCO}_{3}}} v_{\max } \frac{C^{\text {urea }}}{K_{\mathrm{m}}+C^{\text {urea }}}\left(t-\frac{t^{2}}{2 t_{\max }}\right)\right\}\right\} .
\end{aligned}
$$

This formula can be used to calculate the development of the calcium carbonate concentration exactly (for $0 \leq t \leq t_{\max }$ ) at places with a constant urea (and calcium chloride) concentration. This is, for example, at the inflow boundary. In Fig. 1, the calcium carbonate 
Fig. 1 Plot of Eq. 24: the calcium carbonate concentration as a function of time for a constant urea and calcium concentration. The values of the constants in Eq. 24 can be found in Table 1

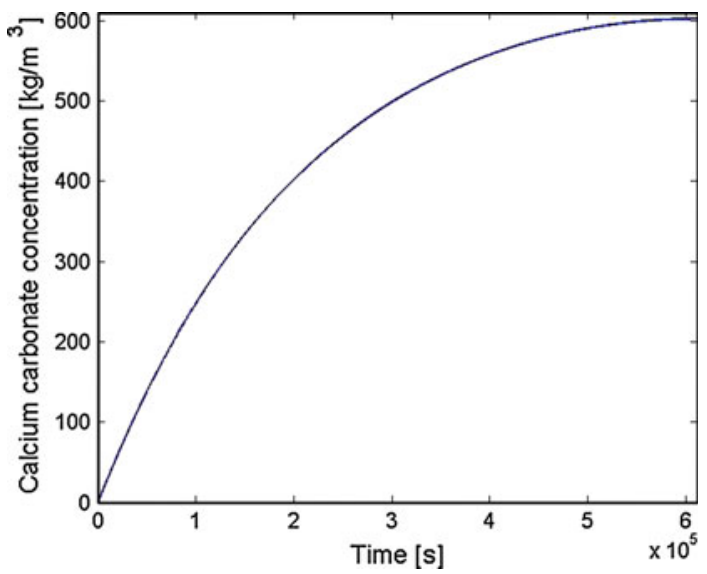

Table 1 The values that are taken for the various constants

\begin{tabular}{lll}
\hline$m_{\mathrm{CaCO}_{3}}=100.1 \mathrm{~kg} \mathrm{kmol}^{-1}$, & $\rho_{\mathrm{CaCO}_{3}}=2,710 \mathrm{~kg} \mathrm{~m}^{-3}$, & $v_{\mathrm{max}}=9.0 \times 10^{-5} \mathrm{kmol} \mathrm{m}^{-3} \mathrm{~s}^{-1}$, \\
$K_{\mathrm{m}}=0.010 \mathrm{kmol} \mathrm{m}^{-3}$, & $c_{\mathrm{in}}=1.0 \mathrm{kmol} \mathrm{m}^{-3}$, & $q_{\text {in }}=5.0 \times 10^{-6} \mathrm{~m} \mathrm{~s}^{-1}$, \\
$d_{\mathrm{m}}=2.0 \times 10^{-4} \mathrm{~m}$, & $p_{1}=100,854 \mathrm{~Pa}$, & $p_{2}=1.00 \times 10^{5} \mathrm{~Pa}$, \\
$\mu=1.15 \times 10^{-3} \mathrm{Pas}$, & $\theta_{0}=0.35$, & $\alpha_{\mathrm{L}}=0.01 \mathrm{~m}$, \\
$\alpha_{\mathrm{T}}=0.001 \mathrm{~m}$, & $L=1.0 \mathrm{~m}$, & $M=0.5 \mathrm{~m}$, \\
$t_{\max }=6.12 \times 10^{5} \mathrm{~s}(=170 \mathrm{~h})$ & &
\end{tabular}

concentration has been plotted as a function of time. The values of the constants in Eq. 24, that has been chosen to plot this figure, can be found in Table 1 .

\section{Numerical Method}

In this section is explained which numerical methods are used to solve the equations in order to do simulations with the model.

\subsection{Numerical Method to Solve the Equations for the Aqueous Species}

Currently, the Biogrout process is applied to sand. In that case, sorption of calcium, urea and ammonium plays an insignificant role. Hence, it can be assumed that the retardation factors for these species are equal to one. In the current model, there are no internal sources or sinks, hence $q_{\mathrm{s}}^{\text {urea }}=q_{\mathrm{s}}^{\mathrm{Ca}^{2+}}=q_{\mathrm{s}}^{\mathrm{NH}_{4}^{+}}=0$. Then, using Eqs. 6, 7 and 8, combining them with Eq. 14, gives the following differential equations for the aqueous species:

$$
\begin{aligned}
\theta \frac{\partial C^{\mathrm{urea}}}{\partial t} & =\nabla \cdot\left[\theta \mathbf{D} \cdot \nabla C^{\mathrm{urea}}\right]-\mathbf{q} \cdot \nabla C^{\mathrm{urea}}-\theta r, \\
\theta \frac{\partial C^{\mathrm{Ca}^{2+}}}{\partial t} & =\nabla \cdot\left[\theta \mathbf{D} \cdot \nabla C^{\mathrm{Ca}^{2+}}\right]-\mathbf{q} \cdot \nabla C^{\mathrm{Ca}^{2+}}-\theta r, \\
\theta \frac{\partial C^{\mathrm{NH}_{4}^{+}}}{\partial t} & =\nabla \cdot\left[\theta \mathbf{D} \cdot \nabla C^{\mathrm{NH}_{4}^{+}}\right]-\mathbf{q} \cdot \nabla C^{\mathrm{NH}_{4}^{+}}+2 \theta r .
\end{aligned}
$$


These differential equations now become linear in the concentration, except for the differential equation for urea, since the reaction term, (20), is nonlinear.

The differential equations for the pressure, the velocities and the concentrations of the aqueous species are solved by the SG finite-element method. First, the weak formulation is derived by multiplication by a test function $\eta \epsilon H^{1}(\Omega)$ and integration over the domain $\Omega$. For the time integration, an IMEX (implicit-explicit) scheme is used. That gives the following weak formulations for the urea concentration:

$$
\begin{aligned}
& \int_{\Omega} \theta^{n} \frac{\left(C^{\text {urea }}\right)^{n+1}-\left(C^{\text {urea }}\right)^{n}}{\Delta t} \eta \mathrm{d} \Omega+\int_{\Omega}\left(\theta^{n} \mathbf{D}^{n} \cdot \nabla\left(C^{\text {urea }}\right)^{n+1}\right) \cdot \nabla \eta \mathrm{d} \Omega \\
& -\oint_{\Gamma} \eta\left(\theta^{n} \mathbf{D}^{n} \nabla\left(C^{\text {urea }}\right)^{n+1}\right) \cdot \mathbf{n} \mathrm{d} \Gamma+\int_{\Omega} \mathbf{q}^{n+1} \cdot \nabla\left(C^{\text {urea }}\right)^{n+1} \eta \mathrm{d} \Omega=-\int_{\Omega} \theta^{n} r^{n+1} \eta \mathrm{d} \Omega,
\end{aligned}
$$

for all $\eta \epsilon H^{1}(\Omega)$, which vanish at location of the boundary where $C^{\text {urea }}$ is prescribed explicitly. Here, only the equation for urea has been given since the other equations are dealt with analogously.

The Newton-Cotes quadrature rules have been used for the development of the element matrices and vectors. Line elements are used in $1 \mathrm{D}$, whereas triangular elements are used in 2D. In both cases linear basis functions are used.

3.2 Numerical Method to Solve the Equations for the Pressure and the Flow

For the pressure, $p$, the following weak formulation is derived:

$$
\begin{aligned}
\int_{\Omega} \frac{k^{n}}{\mu} & \left(\nabla p^{n+1}+\rho^{n} g \mathbf{e}_{\mathbf{z}}\right) \cdot \nabla \eta \mathrm{d} \Omega-\oint_{\Gamma} \eta \frac{k^{n}}{\mu}\left(\nabla p^{n+1}+\rho^{n} g \mathbf{e}_{\mathbf{z}}\right) \cdot \mathbf{n} \mathrm{d} \Gamma \\
& =\int_{\Omega} \frac{m_{\mathrm{CaCO}_{3}}}{\rho_{\mathrm{CaCO}_{3}}} \theta^{n} r^{n} \eta \mathrm{d} \Omega,
\end{aligned}
$$

and for the flow the following:

$$
\begin{gathered}
\int_{\Omega} q_{x}^{n+1} \eta \mathrm{d} \Omega=-\int_{\Omega} \frac{k^{n}}{\mu} \frac{\partial p^{n+1}}{\partial x} \eta \mathrm{d} \Omega, \\
\int_{\Omega} q_{y}^{n+1} \eta \mathrm{d} \Omega=-\int_{\Omega} \frac{k^{n}}{\mu} \frac{\partial p^{n+1}}{\partial y} \eta \mathrm{d} \Omega, \\
\int_{\Omega} q_{z}^{n+1} \eta \mathrm{d} \Omega=-\int_{\Omega} \frac{k^{n}}{\mu}\left(\frac{\partial p^{n+1}}{\partial z}+\rho^{n} g\right) \eta \mathrm{d} \Omega .
\end{gathered}
$$

Also for these equations, the Newton-Cotes quadrature rules have been used for the development of the element matrices and vectors. Line elements are used in 1D, whereas triangular elements are used in 2D. In both cases linear basis functions are used. 


\subsection{Numerical Method to Solve the Equations for the Non-Aqueous Species}

Since the differential equation for the concentration of calcium carbonate, (9), is an ordinary differential equation (in each grid point), it is not necessary to use the finite-element method. Using an IMEX-scheme for the time integration, the following equation can be used to calculate the calcium carbonate concentration on the next time step:

$$
\frac{\left(C^{\mathrm{CaCO}_{3}}\right)^{n+1}-\left(C^{\mathrm{CaCO}_{3}}\right)^{n}}{\Delta t}=m_{\mathrm{CaCO}_{3}} \theta^{n} r^{n+1} .
$$

\subsection{Scheme for Solving the Equations}

In order to do simulations with the model, the time span has been divided into equisized time steps. At each time step, Eqs. 28-33 are solved. First the equation for the pressure, (29), is solved, using the intrinsic permeability, density, porosity and reaction rate from the previous time step. Subsequently, the velocities are calculated, using Eqs. 30, 31 and/or 32. Again, the intrinsic permeability and the density from the previous time step are used. The differential equation for the urea concentration, (28), is solved implicitly, using the porosity from the previous time step. Newton's method is used, to cope with the nonlinearity in the reaction term. Due to the mass balance, in each differential equation for the concentration the same $r$ should be used. This $r$ follows from the differential equation for the urea concentration. The differential equations for the concentrations of calcium and ammonium are also solved using an implicit-explicit method, with the porosity from the previous time step. Subsequently, the equation for the calcium carbonate concentration, (33), is solved, using the porosity from the previous time step and the reaction rate on the new one. Finally, the porosity $(\theta)$ and the intrinsic permeability $(k)$ are recalculated with (11) and (18), respectively. If necessary, also the boundary conditions and the density of the fluid $(\rho)$ are updated. The density of the fluid is calculated with the use of Eq. 19.

\section{Results}

In this section, the results of several simulations with the model are shown. In Subsect. 4.2, some one-dimensional simulations are presented. The configuration and the boundary conditions are given in Subsect. 4.1. Subsection 4.4 contains results from simulations with the two-dimensional model. The configuration and boundary conditions for the various $2 \mathrm{D}$ cases are given in Subsect. 4.3.

Table 1 shows the values that are taken for the various constants. These values are used in both the 1D simulations and the 2D simulations, unless stated otherwise.

\subsection{Configuration and Boundary Conditions for a Simulation with the One-Dimensional Model}

The domain is a line segment with length $L$, which can be the one-dimensional representation of a column with a small diameter and length $L$. The domain is subdivided into 50 (line) elements.

There are several possibilities for boundary conditions. The pressure may be equal to a constant at the inflow boundary and at the outflow boundary as well (the pressure driven case). 
Fig. 2 Configuration of the one-dimensional domain

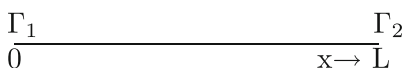

Table 2 Boundary conditions for the pressure and the concentration of urea, calcium and ammonium in the one-dimensional case

\begin{tabular}{|c|c|c|c|c|}
\hline & $p$ & $C^{\text {urea }}$ & $C^{\mathrm{Ca}^{2+}}$ & $C^{\mathrm{NH}_{4}{ }^{+}}$ \\
\hline$\Gamma_{1}$ & $\begin{cases}-\frac{k}{\mu} \frac{\partial p}{\partial n}=q_{\text {in }} & \text { flow driven case } \\
p=p_{1} & \text { pressure driven case }\end{cases}$ & $C^{\text {urea }}=c_{\text {in }}$ & $C^{\mathrm{Ca}^{2+}}=c_{\text {in }}$ & $C^{\mathrm{NH}_{4}^{+}}=0$ \\
\hline$\Gamma_{2}$ & $p=p_{2}$ & $\frac{\partial C^{\text {urea }}}{\partial n}=0$ & $\frac{\partial C^{\mathrm{Ca}^{2+}}}{\partial n}=0$ & $\frac{\partial C^{\mathrm{NH}_{4}}{ }^{+}}{\partial n}=0$ \\
\hline
\end{tabular}

Another possibility is that the flow through the inflow boundary is constant (the flow driven case). These two cases will be simulated with the model. The results will show the influences of these two cases on the calcium carbonate concentration. The boundary at the left-hand side, $\Gamma_{1}$, is the inflow boundary, the boundary at the right-hand side, $\Gamma_{2}$, is the outflow boundary (Fig. 2).

Table 2 displays the boundary conditions that are chosen for the pressure and the concentration of urea, calcium and ammonium in the one-dimensional configuration, for both the flow driven case and the pressure driven case.

The differential equation for the concentration of calcium is equal to the differential equation for urea. Since also the initial conditions and the boundary conditions are equal, the concentration of urea and calcium are equal. Hence, it is not necessary to calculate them both. Only the urea concentration is calculated.

\subsection{Results from a Simulation with the One-Dimensional Model}

This subsection contains results of simulations for a one-dimensional configuration. Figures are shown with the pressure and the velocity at the inflow boundary. It also contains some plots of the urea concentration as a function of space and time and some plots of the calcium carbonate concentration, porosity and intrinsic permeability.

\subsubsection{Pressure and Velocity at the Inflow Boundary}

Figure 3 shows the inflow velocity and the pressure at the inflow boundary for both the pressure driven case and the flow driven case. Initially, the inflow velocity is high in the pressure driven case. Due to the precipitation of calcium carbonate, the porosity and the permeability decrease. Since the pressure at the inflow and outflow boundary stays constant, the inflow velocity decreases. In the flow driven case, the flow rate is constant. Since the porosity and the intrinsic permeability decrease due to the precipitation of calcium carbonate, the pressure at the inflow boundary should increase to keep the flow rate constant.

\subsubsection{Results for Urea}

Figure 4 displays the concentration of urea as a function of the position in the column at several times and Fig. 5 shows the concentration of urea as a function of time at several 

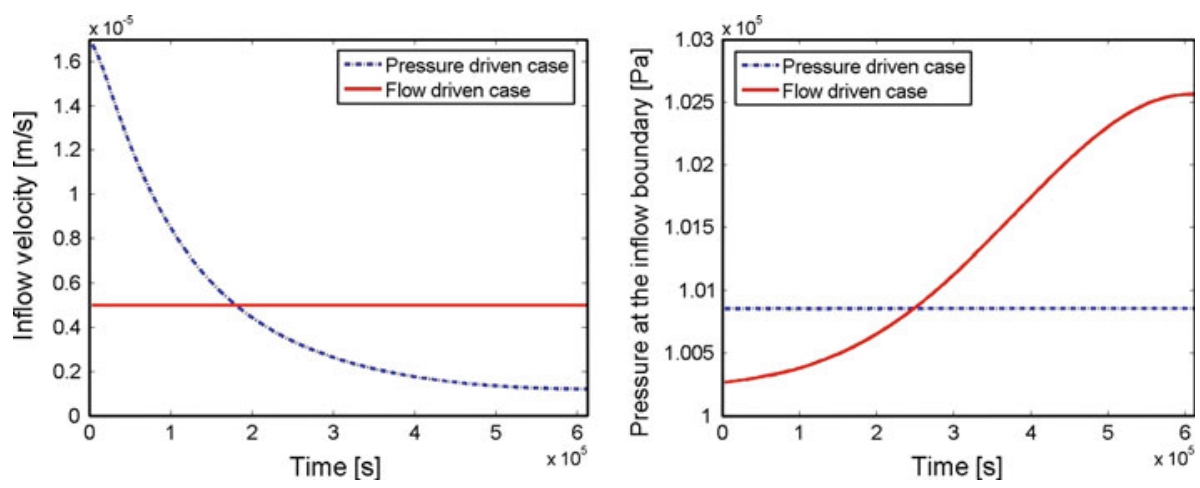

Fig. 3 Left: the inflow velocity as a function of time for the pressure driven case and the flow driven case, right: the pressure at the inflow boundary as a function of time for the pressure driven case and the flow driven case
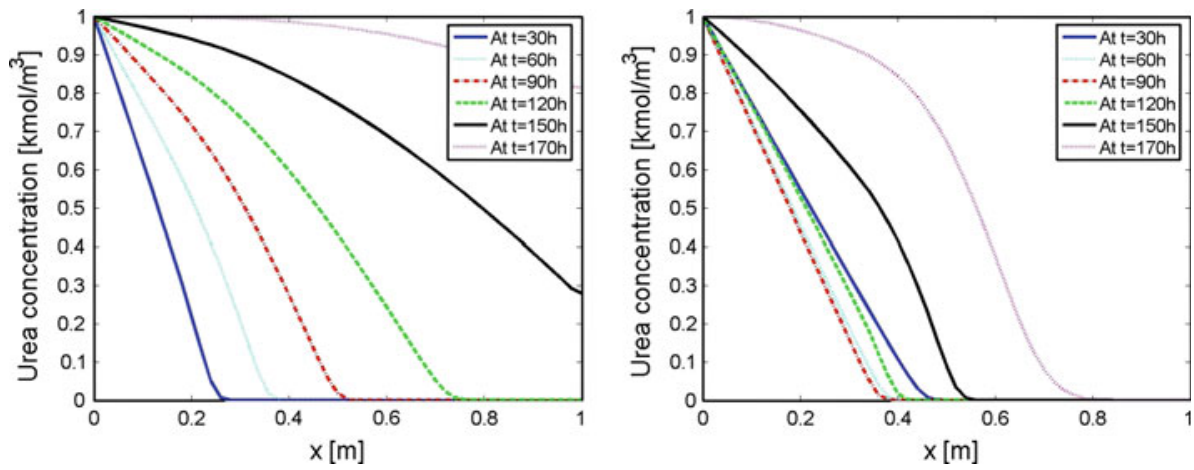

Fig. 4 The urea concentration as a function of $x$ at several times. Left: flow driven case, right: pressure driven case

positions in the column, for both the flow driven case and the pressure case. Figure 6 displays the penetration depth of urea and also $M_{\mathrm{CaCO}_{3}}=\int_{\Omega} C^{\mathrm{CaCO}_{3}} \mathrm{~d} \Omega$, the total amount of calcium carbonate as a function of time, both for the flow driven case and the pressure driven case. The penetration depth has been defined as the largest distance from the inflow boundary for which $C^{\text {urea }} \geq \frac{K_{\mathrm{m}}}{100}$. From Figs. 4 and 5 it can be seen that in the flow driven case, the urea concentration is a non-decreasing function of time at all specified positions in the column. In the pressure driven case, the urea concentration at $x=0.2 \mathrm{~m}$ and $x=0.5 \mathrm{~m}$ decreases in time for some while. These results correspond to the plot of the penetration depth of urea as a function of time in Fig. 6. In the flow driven case, the urea penetrates further and further into the column. At the end, the urea even flows out. In the pressure driven case, initially the penetration depth increases very rapidly. Then it decreases for a while and after that it starts increasing again. The urea does not flow out within a time period of $6.12 \times 10^{5} \mathrm{~s}=170 \mathrm{~h}$.

These results are explained as follows: let us start with the flow driven case. In this case, the flow rate is constant. Initially, the reaction rate of the urea hydrolysis is high. Hence, the urea does not get the possibility to penetrate far into the column. The reaction rate decreases in time. Hence, at a later stage, the urea can penetrate further into the column before all urea molecules react. This effect is enhanced by the fact that, when urea reacts in the presence 

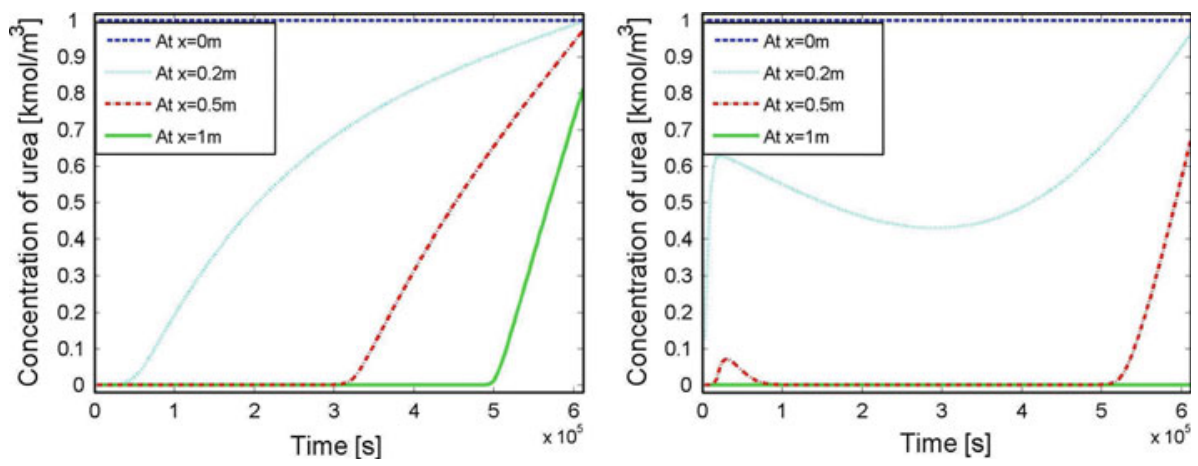

Fig. 5 The urea concentration as a function of time at several positions in the column. Left: flow driven case, right: pressure driven case
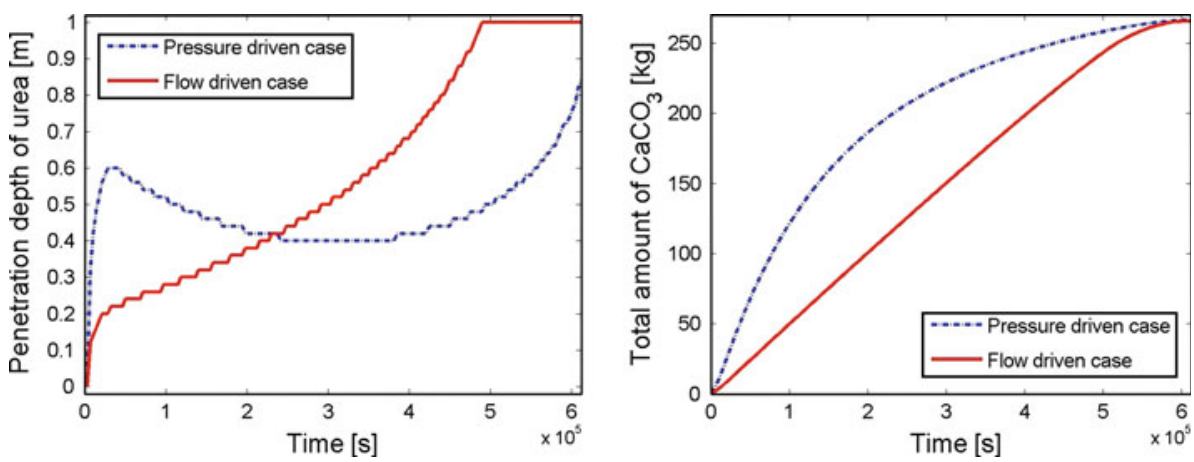

Fig. 6 Left: the penetration depth of urea as a function of time for the pressure driven case and the flow driven case, right: the total amount of calcium carbonate as a function of time for the pressure driven case and the flow driven case

of carbonate, the solid calcium carbonate will be formed. This decreases the porosity. As a result, the pore water velocity, $v$, increases, since $v=\frac{q}{\theta}$. That also causes urea to penetrate further into the column before it is hydrolysed.

In the pressure driven case, initially, the inflow velocity is high, so the urea can penetrate far into the column. Then, the penetration depth decreases and halfway, it starts increasing again. This behaviour of the penetration depth is the result of several phenomena: the porosity and the permeability decrease due to the formation of the solid calcium carbonate. As a consequence, the flow rate decreases too, since the pressure stays constant at the inflow boundary and at the outflow boundary, as can also be seen from Fig. 3. Another phenomenon is the decreasing reaction rate. As a result, the urea can penetrate further into the column before all urea molecules react.

After $170 \mathrm{~h}$, the reaction rate is equal to zero. However, the urea concentration in the column is not immediately equal to the inflow concentration everywhere. During the hours before, there was a reaction from bacterial activity and hence the urea concentration is lower than the inflow concentration (except at the inflow boundary). Only after some hours, the content of the pore volume of the column is fully refreshed and the urea concentration is equal to the inflow concentration everywhere. 

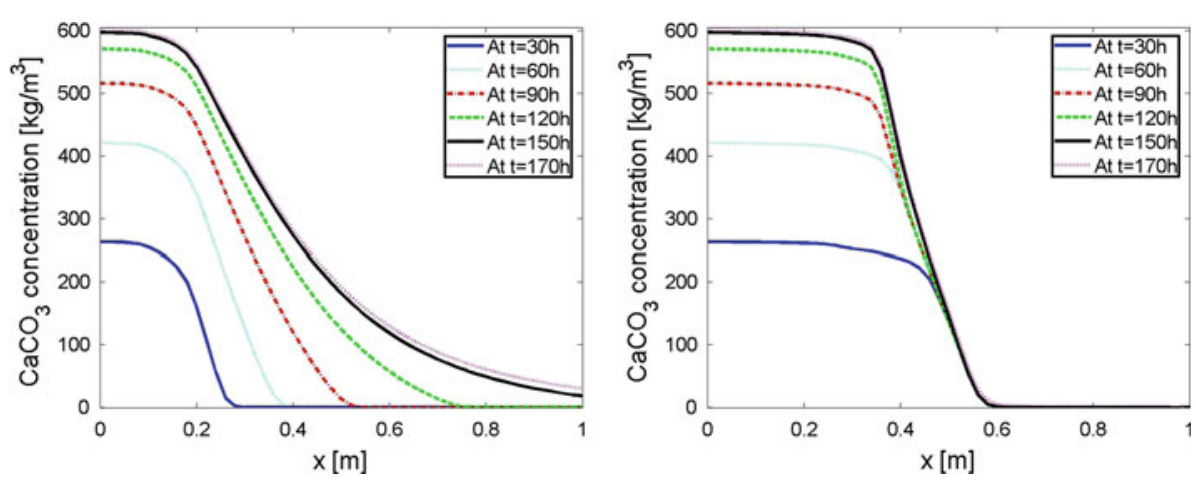

Fig. 7 The concentration of calcium carbonate as a function of $x$ at several times. Left: flow driven case, right: pressure driven case

\subsubsection{Results for Calcium Carbonate, Porosity and Permeability}

Figure 6 also shows the total amount of calcium carbonate in the domain. Except for the last hours, the total amount of calcium carbonate grows linearly in time in the flow driven case. This means that per unit of time the same amount of calcium carbonate is formed. In the model, the reaction rate is linearly decreasing, so this result might look strange at first sight. However, the amount of urea and calcium that flows in per unit of time is constant and the urea and calcium should react or flow out. From Fig. 6 it can be seen that the urea, and hence also the calcium, only flows out during the last hours. Hence, during the rest of the time all the urea and calcium, that flows in, should react. Since the supply of urea and calcium is constant in time, the amount of calcium carbonate that is formed per unit of time is also constant. During the last hours, urea flows out. That explains why the total amount of calcium carbonate is no longer growing that fast.

In the pressure driven case, the total amount of calcium carbonate is not linear in time so the production rate is not constant. From Fig. 6 it can be seen that the urea does not flow out, so only the supply of urea (and calcium) influences the curve. In the pressure driven case, during the first hours the inflow velocity is higher than in the flow driven case. As a result, per unit of time more urea and calcium come in and hence more calcium carbonate will be formed. Hence, the slope of the graph is steeper than in the flow driven case. The inflow velocity decreases in time as can be seen from Fig. 3. Per unit of time less urea and calcium flow in and hence less calcium carbonate can be formed. As a result, the slope of the graph becomes less steep. Eventually, the same amount of calcium carbonate has been formed.

Figure 7 displays the calcium carbonate concentration in the column at several times, both for the pressure driven case and the flow driven case. The relation with the penetration depth of urea is clear. For example, in the first $30 \mathrm{~h}$, in more than the half of the column, calcium carbonate has been formed in the pressure driven case. Eventually, the inflow velocity became that low, that the urea molecules could not reach the end of the column. As a result, no calcium carbonate has been formed in the last part of the column. In the flow driven case, only in the first part of the column calcium carbonate has been formed in the first $30 \mathrm{~h}$. Eventually, the urea molecules reached the end of the column. As a result, everywhere in the column some calcium carbonate has been formed.

At $x=0$, the urea concentration is constant during the process. Hence, using formula (24), the analytic solution can be calculated. The analytical solution is $602.1 \mathrm{~kg} / \mathrm{m}^{3}$. The numerical 

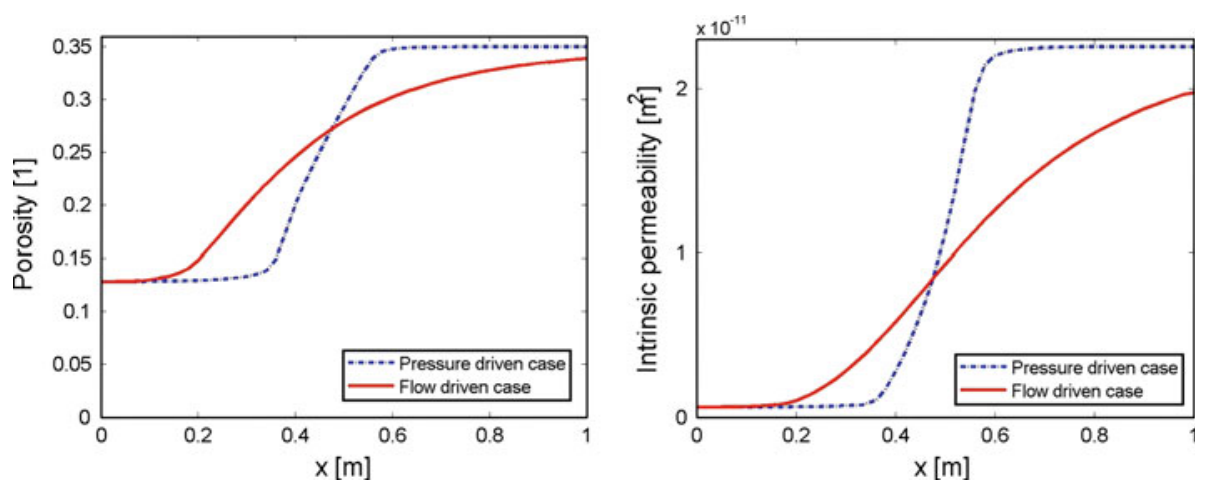

Fig. 8 Left: the porosity as a function of the position at $t=t_{\max }$, right: the intrinsic permeability as function of the position at $t=t_{\max }$

solution at this position, in both the pressure driven case and the flow driven case, is equal to $601.4 \mathrm{~kg} / \mathrm{m}^{3}$. This is a relative error of only $0.12 \%$. By increasing the number of time steps with a factor 2 , the error in this point decreases also with a factor 2 , so the error depends linearly on the size of the time step.

An increase of the generated calcium carbonate concentration, gives a decrease of both the porosity and intrinsic permeability. This phenomenon is confirmed in Fig. 8. At $x=0$, the porosity equals 0.128 , while the initial porosity was 0.35 . Hence, at $x=0$, the porosity has been decreased with a factor 2.7. At $x=0$, the intrinsic permeability was initially $2.26 \cdot 10^{-11} \mathrm{~m}^{2}$ and after the treatment $6.14 \cdot 10^{-13} \mathrm{~m}^{2}$. That means a decrease by a factor of 37 .

In most applications, low-strength cementation (up to $1.5 \mathrm{MPa}$ ) will be sufficient, see van der Ruyt and van der Zon (2009). This corresponds to a calcium carbonate content of approximately $250 \mathrm{~kg} / \mathrm{m}^{3}$, see Van Paassen et al. (2009). In some specific cases, such as preventing liquefaction, only a minor increase in strength (up to $0.15 \mathrm{MPa}$ ) is necessary to prevent sand from flowing, see van der Ruyt and van der Zon (2009). This corresponds with a calcium carbonate content of approximately $80 \mathrm{~kg} / \mathrm{m}^{3}$, see Whiffin et al. (2007). Biogrouted sand with a calcium carbonate concentration of approximately $400 \mathrm{~kg} / \mathrm{m}^{3}$ has the same strength as low-strength concrete, see van der Ruyt and van der Zon (2009).

It depends on the application which injection strategy should be chosen. If one wants to reinforce only the first part of the column, but homogeneously, the pressure driven case (with the parameters chosen as in Table 1) is a good option, as displays Fig. 7. If, for example, a calcium carbonate content of $200 \mathrm{~kg} / \mathrm{m}^{3}$ is asked, the injection can be stopped after $30 \mathrm{~h}$. If one wants at least a minor increase in strength in the whole column, the flow driven case (with the parameters chosen as in Table 1) is a good option (Fig. 7), although a better injection strategy can be chosen since only a minor increase in strength is sufficient.

\subsection{Configuration and Boundary Conditions for a Simulation with the Two-Dimensional Model}

In two dimensions, geometrical effects can be investigated, which was not possible in 1D. Also the influence of density driven flow can be investigated, now. In this subsection, the configuration and boundary conditions are given for five different cases. The first three cases have been constructed to investigate the effect of different permeabilities in one domain. 
The last two cases have been constructed to investigate the phenomenon density flow and the effect of the reaction on it.

In each case is the domain a rectangle which size $L \times M$. The domain is subdivided into 5,000 (triangular) elements. The fluid enters the domain through boundary $\Gamma_{1}$ and flows out through boundary $\Gamma_{2}$. All cases are flow driven. The following five cases will be considered:

- Case 1: the lower half of the domain has a low permeability, inflow through the whole boundary at $x=0$, no density flow;

- Case 2: the lower half of the domain has a low permeability, inflow through the upper part of the boundary at $x=0$, no density flow;

- Case 3: the kernel of the domain has a low permeability, inflow through the lower part of the boundary at $x=0$, no density flow;

- Case 4: density flow, without reaction, inflow through the whole boundary at $x=0$;

- Case 5: density flow, with reaction, inflow through the whole boundary at $x=0$.

In the first two cases, the permeability of the lower half of the domain is initially $10^{-4}$ times the permeability of the upper half, which has been achieved by choosing the mean particle size of the grains in the lower half to be $10^{-2} d_{\mathrm{m}}$. This application accounts for two different adjacent soils. The permeability of the lower half is comparable with the permeability of clay. It is still assumed that there is no sorption. In the first case, the inflow boundary is the whole boundary at $x=0$ and the outflow boundary is the whole boundary at $x=L$.

In cases 2 and 3, the inflow and outflow boundary are only one-third of these boundaries. To have the same amount of urea and calcium chloride flowing into the domain for all cases, the inflow velocity in case 2 and 3 has been chosen to be equal to $3 \cdot q_{\text {in }}$.

In case 3 , there is a rectangle with a low permeability in the middle of the domain. In that rectangle, the mean particle size of the grains also equals $10^{-2} d_{\mathrm{m}}$, like in the less permeable zones in cases 1 and 2 . In the plots with the numerical results the inflow and outflow boundaries are indicated with a thick black line. The low permeable zones are dark.

In case 4 , the focus is on the density flow, without reaction. Urea and calcium chloride are injected with several inflow velocities. For the inflow velocities the following values has been chosen: $q_{\text {inflow }}^{1}=1.0 \times 10^{-6} \mathrm{~m} / \mathrm{s}, q_{\text {inflow }}^{2}=5.0 \times 10^{-6} \mathrm{~m} / \mathrm{s}$ and $q_{\text {inflow }}^{3}=20 \times 10^{-6} \mathrm{~m} / \mathrm{s}$. In the one-dimensional numerical simulations, the inflow velocity equals $q_{\text {inflow }}^{2}$ in the flow driven case. In the pressure driven case, the inflow velocity varies between $q_{\text {inflow }}^{1}$ and $q_{\text {inflow }}^{3}$. The simulation time has been chosen in such a way that the volume of injected fluid is equal.

In case 5, density flow is simulated in combination with reaction.

Table 3 displays the boundary conditions that are chosen. An extra term has been added to the pressure at the outflow boundary to deal with the gravity in the vertical plane.

Table 3 Boundary conditions for the pressure and the concentration of urea, calcium and ammonium in the two-dimensional, flow driven case

\begin{tabular}{|c|c|c|c|c|}
\hline & $p$ & $C^{\text {urea }}$ & $C^{\mathrm{Ca}^{2+}}$ & $C^{\mathrm{NH}_{4}+}$ \\
\hline$\Gamma_{1}$ & $-\frac{k}{\mu}\left(\nabla p+\rho g \mathbf{e}_{\mathbf{z}}\right) \cdot \mathbf{n}= \begin{cases}q_{\text {in }} & \text { case } 1,4 \text { and } 5 \\
3 q_{\text {in }} & \text { case } 2 \text { and } 3\end{cases}$ & $C^{\text {urea }}=c_{\text {in }}$ & $C^{\mathrm{Ca}^{2+}}=c_{\mathrm{in}}$ & $C^{\mathrm{NH}_{4}^{+}}=0$ \\
\hline$\Gamma_{2}$ & $p=p_{2}+\int_{z}^{M} \rho g z \mathrm{dz}$ & $\frac{\partial C^{\text {urea }}}{\partial n}=0$ & $\frac{\partial C^{\mathrm{Ca}^{2+}}}{\partial n}=0$ & $\frac{\partial C^{\mathrm{NH}_{4}^{+}}}{\partial n}=0$ \\
\hline$\Gamma_{3}$ & $-\frac{k}{\mu}\left(\nabla p+\rho g \mathbf{e}_{\mathbf{z}}\right) \cdot \mathbf{n}=0$ & $\frac{\partial C^{\text {urea }}}{\partial n}=0$ & $\frac{\partial C^{\mathrm{Ca}^{2+}}}{\partial n}=0$ & $\frac{\partial C^{\mathrm{NH}_{4}^{+}}}{\partial n}=0$ \\
\hline
\end{tabular}




\subsection{Results from a Simulation with the Two-Dimensional Model}

In this subsection, some two-dimensional results will be shown for the five cases, that are all flow driven. In the first three cases, the focus is on the effect of different permeabilities in one domain. The last two cases have been constructed to investigate the phenomenon density flow and the effect of the reaction on it.

\subsubsection{The Effect of Different Permeabilities in One Domain}

The calcium carbonate concentration (contour plot) and the flow (arrows) after the Biogrout process are shown in Fig. 9 for cases 1 and 2 and in Fig. 10 for case 3.

From the result of case 1, it can be seen that the flow through the lower half of boundary $\Gamma_{1}$ tries to reach the upper half of the domain, where the permeability is much higher. As a result, in the upper half of the domain more calcium carbonate is formed. In case 2, urea and calcium are only flushed into the permeable layer. From the result of case 2, it can be seen that the flow hardly penetrates into the layer with low permeability. Hence, such a layer can
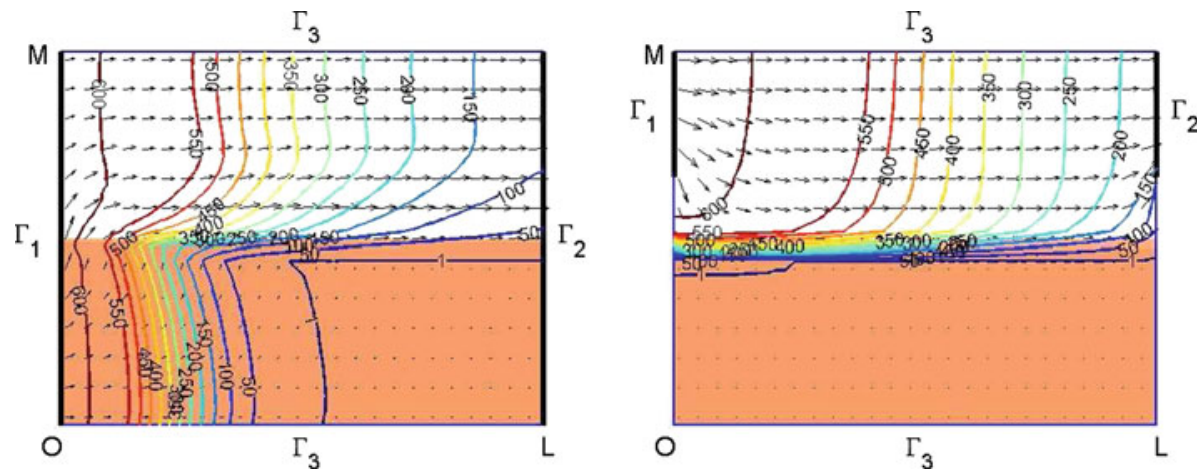

Fig. 9 The flow (arrows) and a contour plots of the calcium carbonate concentration at $t=t_{\max }$ in a domain, of which the lower half is less permeable than the upper half, for different choices for the inflow and outflow boundaries. Left: case 1, right: case 2
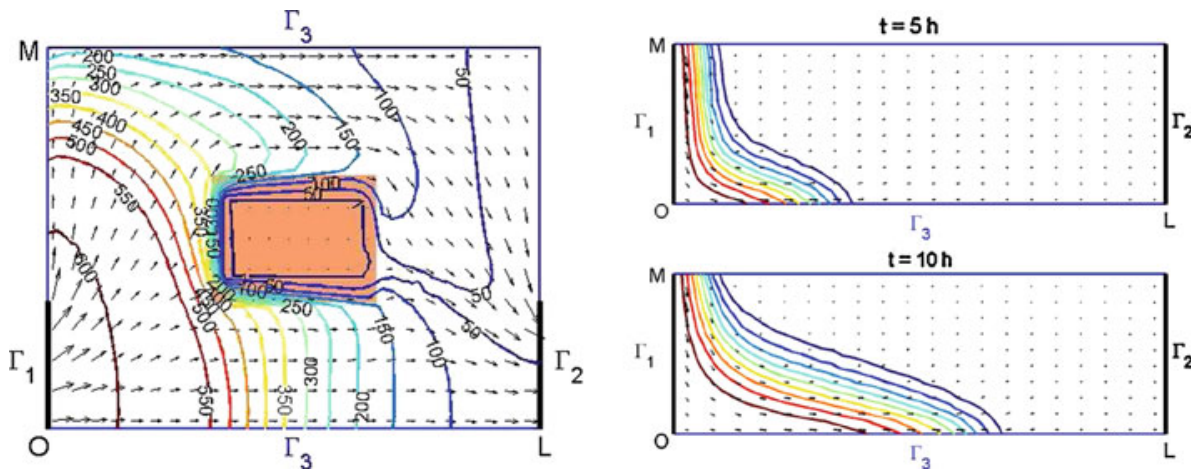

Fig. 10 Left: the flow (arrows) and a contour plot of the calcium carbonate concentration at $t=t_{\max }$ in a domain with a kernel with a low permeability (case 3). Right: the flow (arrows) and a contour plot of the urea concentration (case 4). The inflow velocity is $q_{\text {inflow }}^{1}=1.0 \times 10^{-6} \mathrm{~m} / \mathrm{s}$ 
be seen as an (almost) closed boundary. This is very advantageous if only the upper layer should be reinforced.

From Fig. 10, it can be seen that in case 3 the flow goes through the whole domain, although the inflow and outflow are in the lower part of the domain. Again, in the low permeable zone is hardly any flow, and hence hardly any calcium carbonate is generated there.

\subsubsection{Density Flow and the Effect of the Reaction on it}

From Figs. 10 and 11, it can be seen that there is more density driven flow if the velocity in horizontal direction is low, since the relation between the vertical (density driven) flow and the horizontal flow is large.

In case 5, the biochemical reaction (3) is simulated, too. The inflow velocity equals $q_{\text {in }}$, again. The left plot in Fig. 12 displays a contour plot of the urea concentration after $2 \mathrm{~h}$ and after 40 h. Comparing Fig. 12 with Fig. 11, it can be seen that the urea concentration after $2 \mathrm{~h}$ is lower in the case with reaction than in the case without reaction, since urea is hydrolysed due to microbial activity. Comparing the urea concentration after $2 \mathrm{~h}$ and after $40 \mathrm{~h}$ in Fig. 12, it can be seen that there is more density flow after $2 \mathrm{~h}$. There are two reasons for this. Initially, a solution of 1 molar urea and calcium chloride is injected in water. The density of this
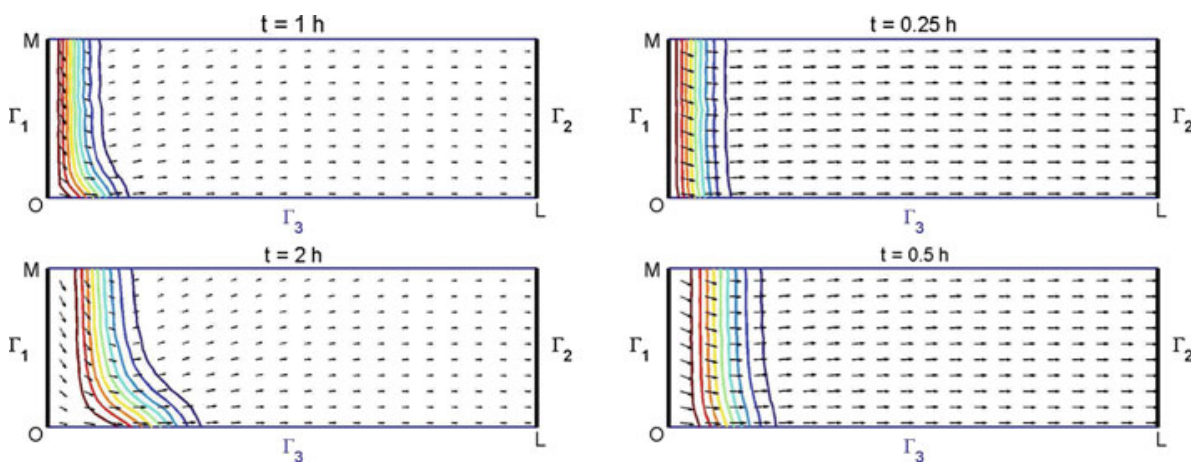

Fig. 11 The flow (arrows) and a contour plot of the urea concentration (case 4). Left: the inflow velocity is $q_{\text {inflow }}^{2}=5.0 \times 10^{-6} \mathrm{~m} / \mathrm{s}$. Right: the inflow velocity is $q_{\text {inflow }}^{3}=20 \times 10^{-6} \mathrm{~m} / \mathrm{s}$
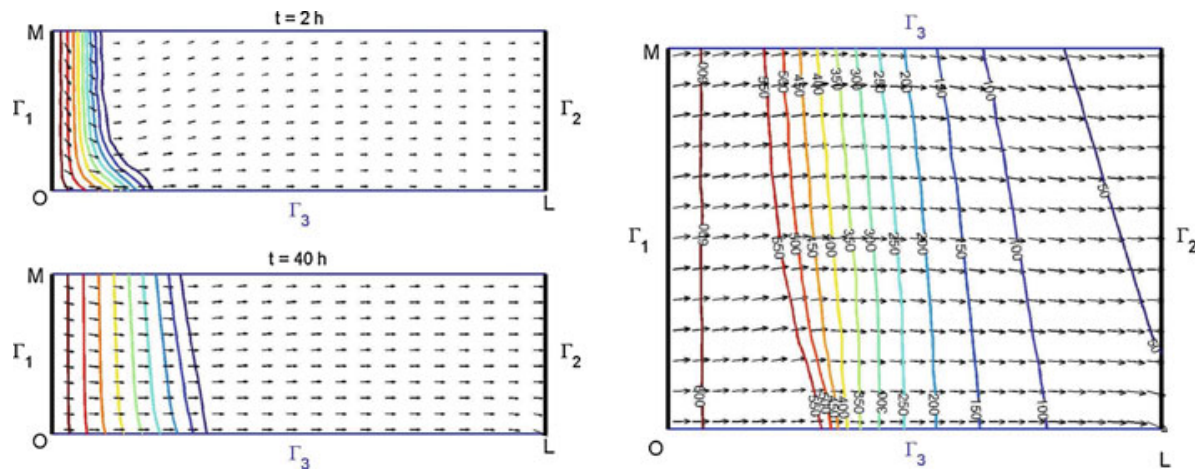

Fig. 12 Contour plot of the urea concentration after 2 and $40 \mathrm{~h}($ left $)$ and the calcium carbonate concentration after the treatment (right) for the case with density flow (case 5). The arrows display the flow 
solution is $1,102 \mathrm{~kg} / \mathrm{m}^{3}$ (see 19). The difference in density between this solution and water is $102 \mathrm{~kg} / \mathrm{m}^{3}$. When urea and calcium chloride react, ammonium is formed. The density of a 2 molar ammonium solution is $1,032 \mathrm{~kg} / \mathrm{m}^{3}$. The difference between the urea/calcium chloride solution and the ammonium solution is smaller than the difference between the urea/calcium chloride solution and water. Hence, there is less density flow, since it is the difference in density that causes density flow. The second reason is the increase in pore water velocity due to the decreasing porosity. As could be seen in Figs. 10 and 11, there is less density flow if the horizontal velocity increases. These two phenomena cause a decrease in density flow.

Initially, when there is relatively much density flow, the urea is in the first part of the column. Hence, in the first part of the column, the largest effect of density flow can be seen. This is also visible in Fig. 12.

\section{Conclusions and Discussion}

A model has been formulated to describe the Biogrout process. The model gives insight into several aspects of the Biogrout process. The Biogrout process influences several properties of the subsoil. The precipitation of the solid calcium carbonate decreases the porosity and the permeability. According to the model, the precipitation of approximately $600 \mathrm{~kg} / \mathrm{m}^{3}$ calcium carbonate at an initial porosity of 0.35 causes a decrease in the porosity by only a factor 3 , while the permeability decreases by a factor 37 . A consequence of a decreasing permeability is that the pressure should increase to keep up the same flow rate, or, if the pressure is constant, that the flow rate decreases.

In the first part of the column, more calcium carbonate precipitated than in the end of the column. The reason is that many urea molecules did already react in the first part of the column and could not reach the end of the column within the simulation time. The penetration depth of urea especially depends on the reaction rate and the inflow velocity. For this configuration and these values for the several constants, the pressure driven case resulted in a rather homogeneous calcium carbonate concentration in the first part of the column, while at the end of the column (almost) nothing precipitated. In the middle of the column, the calcium carbonate concentration decreases very fast. The flow driven case results in a calcium carbonate concentration that slowly decreases while the distance to the inflow boundary increases. In comparison with the pressure driven case, no steep gradients are present.

When injecting a urea and calcium chloride solution with a small inflow velocity, the effect of density flow is larger than in the case that the same volume is injected, but with a high-injection velocity.

Initially, the urea and calcium chloride solution is injected into water. Due to the reaction, the density of the fluid decreases. Since the differences in densities are not that large any more, there is less density flow.

At the places where the urea and calcium concentration are constant, the calcium carbonate concentration can be calculated, using an analytic expression. In the model, the urea and calcium concentration were constant at the inflow boundary. The theoretical solution corresponds well with the numerical solution, although the time steps where reasonable large.

The model has been created under several assumptions. These assumptions should be validated using experiments. The first assumption was that the process is governed by the biochemical reaction (3). However, in reality this reaction happens in several steps. Some of these steps are equilibrium reactions that depend on the $\mathrm{pH}$. Other assumptions are that the 
retardation factors are equal to 1 and that the total volume of the fluid does not change due to the hydrolysis of urea and the precipitation of calcium carbonate. These assumptions should be verified.

It has also been assumed that calcium carbonate precipitates locally and will not be transported. Calcium carbonate can precipitate in several ways. It can attach to sand grains but can also form crystals. When these crystals are large enough, they will stick in the pore throats and it can be assumed that they are not transported. However, when these crystals are small, probably they can be transported. It should be verified if this phenomenon is really negligible.

Another assumption is that the distribution of bacteria is homogeneous and that the reaction rate has a linear decay in time. These bacteria have been placed in the subsurface by injecting a solution with bacteria and a fixation fluid. The bacteria are assumed to attach to the solid particles and this effect will be enlarged by the fixation fluid. This fixation fluid causes the flocculation of bacteria and hence they cannot easily flow out anymore but will be filtered by the sand. It is not likely that these processes will result in a homogeneous bacteria distribution. The formula for the reaction rate includes the saturation constant $K_{\mathrm{m}}$. Experiments should be done to determine the value of this constant. From experiments, it is known that the reaction rate decreases in time, but the reasons are not yet clear. Hence, as a starting point, a reaction rate has been assumed, that has a linear decay in time. Probably, this decay is not linear. Further research should be done to find out which circumstances influence the reaction rate and a better formula for the reaction rate should be found.

To calculate the intrinsic permeability the Kozeny-Carman relation has been used. This empirical relation turns out to be a good relation for many cases. It is questionable if this is also true for the Biogrout process, with its changing porosity. Another difficulty is the choice of the mean particle size $d_{\mathrm{m}}$ in this relation. Perhaps, the mean particle size needs to be adapted as a result of calcium carbonate precipitation. If the calcium carbonate mainly attaches to the sand grains, the mean particle size increases. If mainly crystals are formed that are smaller than the sand grains, the mean particle size decreases. Experiments need to be done to find out what actually happens. Furthermore, alternative relationships between the intrinsic permeability and the porosity have been reported. An example concerns the study due to Costa (2006), where a fractal pore-space geometry has been assumed. In this study, any relation can be incorporated, but since this issue is not crucial here, the use of the classical Kozeny-Carman relation is maintained.

The last assumption is that the viscosity is constant and not dependent on the various concentrations. This is also a simplification of reality.

Hence, although the assumptions should be verified, the model is a good tool to get insight into the process.

For engineering design, it is necessary to know the relation between the calcium carbonate and the mechanical characteristics of the soil. For the strength of the soil, it is important where the calcium carbonate precipitates. Calcium carbonate, connecting sand grains, will give a contribution to strength, while loose crystals hardly will. Furthermore, calcium carbonate is a polymorph, which means that several mineral types exist with similar molecular composition (amorphous calcium carbonate, vaterite and calcite). The crystal properties (size, shape and mineral type) are dependent on, among others, the precipitation conditions (Van Paassen 2009) and will result in a different contribution to strength. In order to find correlations between calcium carbonate content and strength of Biogrouted sand, several cores have been collected from a field scale Biogrout experiment and have been tested. In Van Paassen et al. (2009), correlations between unconfined compressive strength (UCS), $\mathrm{CaCO}_{3}$ content and dry density are found from approximately 50 tests. Several other tests have been done to find 
the strength at different confining pressures. Using these test results, failure criteria (angle of internal friction and cohesion) were determined. These failure criteria can be used to assess the stability of (biologically) cemented soil.

Acknowledgments Special thanks to Jitse Pruiksma (Deltares) and Leon van Paassen (Delft University of Technology) for partly deriving the differential equations.

Open Access This article is distributed under the terms of the Creative Commons Attribution Noncommercial License which permits any noncommercial use, distribution, and reproduction in any medium, provided the original author(s) and source are credited.

\section{References}

Atkins, H.L., Shu, C.-W.: Quadrature-free implementation of discontinuous galerkin method for hyperbolic equations. AIAA J. 36(5), 2440-2463 (1998)

Bachmeier, K.L., Williams, A.E., Warmington, J.R., Bang, S.S.: Urease activity in microbiologically-induced calcite precipitation. J. Biotechnol. 93, 171-181 (2002)

Banga, S.S., Galinata, J.K., Ramakrishnan, V.: Calcite precipitation induced by polyurethane-immobilized Bacillus pasteurii. Enzym. Microb. Technol. 28, 404-409 (2001)

Bear, J.: Dynamics of Fluids in Porous Media, pp. 119-194. Dover Publications, New York (1972)

Celia, M.A., Kindred, J.S., Herrera, I.: Contaminant transport and biodegradation, a numerical model for reactive transport in porous media. Water Resour. Res. 25(6), 1141-1148 (1989)

Cockburn, B.: An Introduction to the Discontinuous Galerkin Method for Convection Dominated Problems. School of Mathematics, University of Minnesota, Minneapolis, pp. 151-268 (1998)

Cockburn, B., Shu, C.-W.: The local discontinuous Galerkin method for time-dependent convection-diffusion systems. SIAM J. Numer. Anal. 35(6), 2440-2463 (1998)

Costa, A.: Permeability-porosity relationship: a reexamination of the Kozeny-Carman equation based on a fractal pore-space geometry assumption. Geophys. Res. Lett. 33, L02318 (2006). doi:10.1029/ 2005GL025134

DeJong, J.T., Fritzges, M.B., Nusslein, K.: Microbially induced cementation to control sand response to undrained shear. J. Geotech. Geoenviron. Eng. 132(11), 1381-1392 (2006)

DeJong, J.T., Mortensen, B.M., Martinez, B.C., Nelson, D.C.: Bio-mediated soil improvement. Ecol. Eng. 36(2), 197-210 (2010)

Ewing, R.E., Wang, H.: A summary of numerical methods for time-dependent advection-dominated partial differential equations. J. Comput. Appl. Math. 128, 423-445 (2001)

Heinrich, J.C., Huyakorn, P.S., Zienkiewicz, O.C.: An 'upwind' finite element method for two-dimensional convective transport equation. Int. J. Numer. Methods Eng. 11, 131-143 (1977)

Krivodonova, L.: Limiters for high order DG methods. J. Comput. Phys. 226, 879-896 (2007)

Le Beau, G.J., Tezduyar, T.E.: Finite element computation of compressible flows with the SUPG formulation. In: Engleman, M.S., Reddy, J.N. (eds.) Advances in Finite Element Analysis in Fluid Dynamics, FED-vol. 123, pp. 21-27. ASME, New York (1991)

Lichtner, P.C., Steefel, C.I., Oelkers, E.H.: Reactive transport in porous media. Rev. Mineral. 34, 83-125 (1996)

Lohner, R., Morgan, K., Zienkiewicz, O.C.: The solution of non-linear hyperbolic equation systems by the finite element method. Int. J. Numer. Methods Fluids 4, 1043-1063 (1984)

Nemati, M., Voordouw, G.: Modification of porous media permeability, using calcium carbonate produced enzymatically in situ. Enzym. Microb. Technol. 33, 635-642 (2003)

Stocks-Fischer, S., Galinat, J.K., Bang, S.S.: Microbiological precipitation of $\mathrm{CaCO}_{3}$. Soil Biol. Biochem. 31, 1563-1571 (1999)

van der Ruyt, M., van der Zon, W.: Biological in situ reinforcement of sand in near-shore areas. Proc. Inst. Civil Eng. Geotech. Eng. 162, 81-83 (2009)

Van Paassen, L.A.: Biogrout, ground improvement by microbially induced carbonate precipitation. PhD thesis, Delft University of Technology, pp. 1-195 (2009)

Van Paassen, L.A., Pieron, M., Mulder, A., Van der Linden, T.J.M., Van Loosdrecht, M.C.M., Ngan-Tillard, D.J.M.: Strength and deformation of biologically cemented sandstone. In: Vrkljan (ed.) Proceedings of the ISRM Regional Conference EUROCK 2009-Rock Engineering in Difficult Ground ConditionsSoft Rocks and Karst, pp. 405-410, Dubrovnik, Croatia, 29-31 October 2009 
Weast, R.C.: 1980 Handbook of Chemistry and Physics, pp. D-229-D-276. CRC Press, Boca Raton (1980)

Whiffin, V.S.: Microbial $\mathrm{CaCO}_{3}$ precipitation for the production of biocement. $\mathrm{PhD}$ thesis, Murdoch University, Perth, Australia, pp. 1-154, (2004)

Whiffin, V.S., Paassen, L.A.van , Harkes, M.P.: Microbial carbonate precipitation as a soil improvement technique. Geomicrobiol. J. 24(5), 417-423 (2007)

Zheng, C., Bennett, G.D.: Applied Contaminant Transport Modeling, pp. 3-79. Van Nostrand Reinhold, New York (1995)

Zienkiewicz, O.C., Taylor, R.L., Taylor, R.L.: The Finite Element Method for Solid and Structural Mechanics, pp. 1-596. Butterworth-Heinemann, Oxford (2005) 